\title{
Reflexões e significados sobre competências docentes no ensino médico
}

\author{
Maria das Mercês Borém Correa Machado \\ Cristina Andrade Sampaio \\ Simone Moreira de Macedo \\ Maria Fernanda Santos Figueiredo \\ João Felício Rodrigues Neto \\ Isabella Gomes Lopes \\ Maísa Tavares de Souza Leite
}

Resumo: Este estudo tem como objetivo compreender o significado de competência na percepção dos docentes dos módulos de Habilidades e Atitudes. Trata-se de uma pesquisa descritiva e exploratória. A escolha do referencial teórico e metodológico considerou a perspectiva hermenêutica. O estudo foi realizado em uma universidade pública com docentes do curso de Medicina, por meio de entrevista individual e não estruturada. Os dados foram submetidos à análise do discurso evidenciando as categorias empíricas: "Competência como eixo norteador e estruturante às necessidades educacionais"; "Docência na educação médica: a prática profissional possibilita habilidades" e "Estratégias para o desenvolvimento docente". Considera-se que as mudanças requeridas no curso médico precisam encontrar apoio na gestão e na liderança dos professores, na implementação de um programa de desenvolvimento do corpo docente, que se tornará um valioso instrumento de reflexão para os educadores, a fim de melhorar o exercício da docência no curso médico.

Palavras-chave: Competência profissional. Educação médica. Docentes de medicina.

\section{Reflections and meaning of the teachers skills in medical education}

Abstract: This study aims to understand the meaning of competence in the perception of the teachers in the modules of Skills and Attitudes. It's a descriptive and exploratory research. The choice of the theoretical and methodological framework considered the hermeneutic perspective. The study was conducted in a public university in the medical school, through individual and unstructured interview. The data were submitted to discourse analysis showing the empirical categories, "Competence as a guiding and structuring axis to educational needs"; "The teaching in medical education: professional practice and enabling skills" and "Strategies for teacher development". It is considered that the required changes in medical school need to find support in the management and leadership of teachers in the implementation of a faculty development program, which will become a valuable tool of reflection for educators in order to improve exercise of teaching in the medical school.

Key words: Professional competence. Medical education. Medical faculty. 


\section{Introdução}

As rápidas transformações do mundo, da sociedade e do conhecimento acumuladas na era da pós-modernidade produzem repercussões na educação e na escola. Nesse contexto, a educação médica tem vivenciado os desafios das mudanças, requerendo novos saberes no cenário educacional, social e político da sociedade, o que demanda um novo perfil de competências para a docência no ensino superior (LAMPERT et al., 2009).

A noção de competência tem permeado o processo educacional como um todo, influenciando o papel profissional do docente. O conceito de competência é polissêmico e, de maneira geral, apresenta-se associado à ação. A competência, para além da mobilização de recursos, conhecimentos, habilidades e atitudes, possui características pessoais e profissionais na resolução de problemas, o que evidencia a busca pela excelência, traduzida na prática como objetivo principal do exercício adequado das competências profissionais. Os diversos cenários da atuação médica estimulam uma constante reflexão sobre sua atuação, o que permite melhorar a performance docente assistencial (PINHEL; KURCGANT, 2007; BRASIL, 2014; FRANCO et al., 2014).

Essa perspectiva aponta para a competência docente vinculada ao conhecimento teórico-prático. O indivíduo que assim se capacita ancora sua prática não apenas no conhecimento que o professor detém, mas também nas capacidades e habilidades que permitem eclodir esquemas de pensamentos que possibilitem a mobilização, a orquestração e a sistematização de recursos pertinentes para a aplicação desses saberes (PINHEL; KURCGANT, 2007). Sinaliza o construir, com autonomia, o conhecimento (CHIESA et al., 2007).

Destaca-se a importância de se considerarem os aspectos didático-pedagógicos, técnico-científicos, assistenciais, de gestão e as metodologias ativas de ensino-aprendizagem, tendo como foco o estudante, além de um inter-relacionamento entre as áreas (LAMPERT et al., 2009; CAMPOS et al., 2007). Para tanto, deve-se contextualizar a sociedade, as políticas vinculadas à saúde e a consequente importância na construção da rede entre ações interdisciplinares e de co-responsabilização (AZEVEDO et al., 2013).

Dessa forma, mais do que a formação técnica e científica, torna-se necessária ao docente uma atuação competente voltada para a transformação social (PINHEL; KURCGANT, 2007). No entanto, de modo geral, os processos de seleção e contratação do docente universitário têm priorizado aspectos da competência relacionados à transmissão de conhecimentos e à realização de algumas atividades práticas. Esse olhar tem o professor como o centro maior das informações acerca do conhecimento a ser construído. E faz dele o deten- 
tor de um conjunto de saberes, cuja transmissão tem sido apresentada como imperiosa para salvaguardar as necessidades do sistema socioeconômico em que os docentes e alunos se inserem (AZEVEDO et al., 2013).

A formação didático-pedagógica para o educador passa a ser condição para o exercício das atividades como professor nas Instituições de Ensino Superior (IES). Todavia, essa formação depara-se com a resistência às mudanças, a personalização e o status cultural de que ser professor no ensino superior não demanda conhecimento e formação nas dimensões de ensino e aprendizagem (PIMENTA; ANASTASIOU, 2002; COSTA, 2007; LAMPERT et al., 2009).

Ao estabelecer os princípios, os fundamentos e as finalidades da formação em Medicina, o Conselho Nacional de Educação/Câmara de Educação Superior (CNE/CES), por meio da Resolução $\mathrm{n}^{\circ}$ 3, de 20 de junho de 2014, instituiu orientações às IESs, permitindo mudanças do cenário metodológico das universidades, a partir de uma proposta de trabalho, segundo a qual os docentes e discentes desempenhem papel decisivo, a fim de dar corpo à atitude interdisciplinar. A ação pressupõe o comprometimento de todos os profissionais envolvidos no processo ensino-aprendizagem e exige que cada um, em sua prática, promova a atenção, gestão, educação em saúde e a melhoria da qualidade de vida (BATISTA; BATISTA, 1978; BRASIL, 2014).

Considera-se que a atenção às competências necessárias aos professores está de acordo com a política institucional de desenvolvimento docente, requerida para promover a academia em sua excelência. Essa política promove a reflexão do docente sobre qual percepção e significado ele atribui à competência pedagógica, e que estratégias utilizar para melhorar sua prática como médico-docente.

No curso médico estudado, o Projeto Pedagógico Curricular (PPC) tem como metodologia a Aprendizagem Baseada em Problemas (ABP). O PPC prevê o desenvolvimento de atividades de integração teórica e prática nos sete primeiros períodos, organizados em forma de módulos, que permitem reunir os conteúdos, dando atenção aos problemas mais prevalentes da comunidade: Módulo de Conteúdo Específico (MCE); Módulo de Habilidades e Atitudes (MHA); Módulo de Interação, Aprendizagem, Pesquisa, Serviço, Comunidade (IAPSC). O oitavo período é organizado em atividades ambulatoriais de especialidades e apresentações clínicas. O nono, o décimo, o décimo primeiro e o décimo segundo períodos são organizados em atividades em estágios e compõem o internato médico (UNIMONTES, 2014).

Nesse sentido, é que se propôs a realização deste trabalho, com o objetivo de compreender o significado de competência para docentes de Medicina do módulo de Habilidades e Atitudes em uma universidade pública, após 12 anos de implantação dos métodos ativos de aprendizagem. 


\section{Metodologia}

Tratou-se de uma pesquisa de natureza qualitativa, realizada em um curso de Medicina de uma universidade pública estadual.

A escolha do referencial teórico e metodológico considerou a perspectiva hermenêutica (RICOEUR, 1978; GADAMER, 1999), que contribuiu para o desvelamento do significado da docência para o professor do curso médico.

Os participantes desta pesquisa foram docentes que atuavam nos módulos de Habilidades e Atitudes e professores do oitavo período do curso de Medicina, selecionados a partir do seguinte critério de inclusão: ser docente do curso médico há pelo menos seis meses.

A coleta de dados foi realizada no ano de 2012, por meio de entrevista aberta, guiada pelo tema norteador: significado e visão de competências. As entrevistas, após transcrição, foram submetidas à análise do discurso.

$\mathrm{Na}$ análise, os sentidos relacionados ao discurso e seus efeitos vão além do texto, valorizando as entrelinhas, os processos de significação, as convergências e divergências, relacionando o interdiscurso e o intradiscurso (PÊCHEUX, 2002). As categorias empíricas foram confrontadas com as analíticas, buscando-se as relações entre ambas, considerando as subjetividades, os ambientes das experiências e motivações, percebendo os enfoques e significados (MINAYO, 2010).

O estudo foi conduzido após a apreciação do Comitê de Ética em Pesquisa da Universidade Estadual de Montes Claros - Unimontes, aprovado segundo o parecer 55818/12.

\section{Resultados e Discussão}

Os discursos analisados dos docentes entrevistados revelaram três categorias empíricas: "Competência como eixo norteador e estruturante às necessidades educacionais", "Docência na educação médica: a prática profissional possibilita habilidades" e "Estratégias para o desenvolvimento docente".

\section{Competência como eixo norteador e estruturante às necessidades educacionais}

Na percepção do docente dos módulos de Habilidades e Atitudes, os conhecimentos são construídos a partir de sua experiência profissional e na prática médica. A análise reflexiva sobre o significado de competência pedagógica foi entendida como o conhecimento técnico-científico que o docente possui: 
[...] foi baseado (o ensino das habilidades) na minha experiência como pediatra. (E2)

[...] então, como eu tinha aquela minha vivência da prática [...] fiz opção em ficar no ambulatório com habilidade e atitude, no qual percebo que tenho mais facilidade, competência e habilidade para trabalhar. (E12)

No meu caso, como sou especialista, eu sempre trabalhei como instrutora do modulo de habilidades. É o que me interessa mais. É mais agradável [...] é continuar como estou, trabalhando na minha área. (E4)

Os professores exercem a docência em Habilidades e Atitudes a partir da prática como médicos, afinidade que oportuniza contribuir em sua qualificação docente. A relevância desse entendimento deve-se ao seu caráter de eixo norteador e estruturante e à experiência profissional, que, no exercício de docência e prática médica, consolida e edifica a especialização. Esse domínio científico dos saberes construídos traz significado de competências e habilidades ao próprio aprendizado. Ao atuar no processo ensino-aprendizagem, essas competências são ampliadas pela prática médica que concretiza e diversifica o conhecimento, auxiliando no processo da formação docente. Esse diferencial ajusta-se à contribuição que cada médico-docente acrescenta ao cotidiano do ensino médico, pois precisa da habilidade ao estabelecer o vínculo entre sua prática e o repertório de seus conhecimentos (agregados ao preparo do docente), utilizando suas aptidões e experiências nas atividades que desempenha (FRANCO et al., 2014).

Percebe-se que a compreensão de competência está relacionada ao conhecimento específico da área de formação do professor:

Sempre procurei participar das mudanças que ocorreram na Unimontes. Fui em treinamentos e procurei participar. Às vezes nos congressos médicos tem palestras, partes didática, mesmo sobre PBL, metodologia cientifica e sempre procuro participar de algum tipo de formação para melhorar nessa área. (E4)

Nesse sentido, a formação contínua remete a um investimento pessoal, um trabalho livre e criativo sobre os percursos e os projetos próprios, com vista a uma construção de identidade, que é também uma identidade profissional. Falar de formação contínua é falar de uma autonomia contextualizada do docente. Implica valorizar paradigmas de formação que gerem a preparação de professores que assumiram a responsabilidade por seu próprio desenvolvimento profissional e que participam, como protagonistas, do desenvolvimento das 
políticas educativas (NÓVOA, 2002).

[...] fui chamada para o curso de Medicina [...] tenho competência para falar sobre a comunicação no curso médico, me preparei para isso, estudei como comunicar na relação médico-paciente e estou sempre lendo [...]. (E5)

O professor tem que ter a competência do saber teórico quando se predispõe a fazer aquela habilidade que você deve fazer... você deve ter a habilidade. No caso do $3^{\circ}$ periodo de Semiologia, deve ter saber a habilidade do relacionamento interpessoal com o paciente também. Porque você está transmitindo aquilo para o aluno. (E4)

A relação entre conhecimento e prática como processo pelo qual o professor se aperfeiçoa e se desenvolve, encontra-se catalisada por meio do exercício da docência, uma prática que encerra o desafio de articular conteúdos, métodos e teoria (MACHADO, 2009). O compreender por meio da razão e/ou da experiência revela ação e interação e desvela as relações entre o saber construído ao longo dos anos e a perspectiva da finalidade da competência em práticas cotidianas.

A formação vai além de treinar o educando no desempenho de destrezas; o importante não é transmitir conteúdos específicos, mas despertar uma nova forma de relação com a experiência vivenciada. Nesse sentido, o ato educativo deve ser sempre um ato de recriação, de re-significação de acepções (FREIRE, 1997; COSTA, 2007).

Vale enfatizar que as escolas médicas têm buscado discutir sobre a qualidade da educação e as propostas curriculares ditas "inovadoras" - necessárias para avançar e assegurar aprendizagens imprescindíveis ao desenvolvimento.

Ao perceber esse movimento, os entrevistados têm demonstrado interesse por essas questões, conforme verificado nos depoimentos abaixo:

Sempre procurei participar das mudanças que ocorreram [...] fui a treinamentos [...]. (E4)

[...] fiquei sabendo de um curso sobre PBL e eu disse vou ver o que é isso quero saber o que é isso [...]. (E5)

A proposta da Lei de Diretrizes e Bases da Educação e das Diretrizes Curriculares para o Curso de Medicina apontam para as propostas curriculares inovadoras e passam a exigir dos docentes envolvidos interação, diálogo entre saberes e vivência pedagógica nessas dinâmicas. No entanto, professores mé- 
dicos, em sua maioria, não se capacitam pedagogicamente para o exercício da docência em IES (MORAN; MASETTO; BEHRENS, 2000).

Os docentes desta pesquisa reconhecem, ainda, que a competência perpassa pela formação integral do homem, o que requer a superação do processo de fragmentação do ensino e o aprimoramento do ser docente, como observado nos seguintes discursos:

Então, nós estamos entendendo que o nosso professor precisa também de habilidades e atitudes para fazer habilidades com o nosso aluno [...] e precisa ter conhecimento sobre o que está sendo visto nos módulos do mesmo periodo. (E8) Você precisa de um pouco da didática [...]. (E4)

Para tanto, no cenário educacional atual, torna-se fundamental que o professor reconheça as novas facetas do papel docente como facilitador, orientador e incentivador do conhecimento (MASETTO, 2002), em que a interdisciplinaridade exercida no contexto da prática docente possa atuar nas unidades de ensino em saúde e absorva a complexidade do cotidiano médico e atenda as exigências de saúde da sociedade. Dessa forma, a aprendizagem faz-se decorrente da prática reflexiva de situações desafiadoras, com dimensões interativas. Atualmente, os docentes reescrevem suas histórias sobre seus saberes, sobre ensinar e aprender, sobre didáticas e pedagogias ao reencontrar os pares. A reorientação na educação médica abre horizontes, modifica e incrementa o cotidiano pedagógico de experiências curriculares e metodológicas, o que fortalece e estimula a construção do conhecimento mediada pela interdisciplinaridade (MACHADO, 2009).

\section{Docência na educação médica: a prática profissional possibilita habilidades}

Percebeu-se, nessa categoria, que a inserção do profissional na docência do curso de Medicina, muitas vezes, tem privilegiado a técnica e o conhecimento, e ocorre sem que o profissional se tenha planejado para isso. O objetivo é tão somente suprir a carência de docentes naquela área, sem considerar a devida capacitação para a função a assumir, conforme verificado no depoimento abaixo:

De repente eu cai nas Habilidades. Eu estava no Pronto Atendimento e me chamaram, porque estava faltando um professor de Habilidade. (E1) 
Essa forma de inserção dos professores na profissão docente por convite, necessidade administrativa e pedagógica, pode levar a uma trajetória de formação influenciada pelo autodidatismo, com uma lacuna na formação didático-pedagógica (COSTA, 2007; CANUTO; BATISTA, 2009). Tal situação associa-se à preocupação das escolas de Medicina em formar o médico para atuar apenas em suas competências profissionais, ficando uma falha na formação de professores médicos (COSTA, 2007).

Os entrevistados referiram que iniciaram a docência sem conhecer o Projeto Pedagógico do Curso e sem terem habilidade para utilizar a metodologia de aprendizagem adotada pelo curso médico, que, na instituição estudada, é a Aprendizagem Baseada em Problemas - ABP:

[...] assim que assumimos como professor, não recebemos informações como: este aqui é o PPC. Hoje percebo a importância de conhecer o PPC. (E7)

A ABP eu não conhecia nada. Estudei no tradicional, não tinha vivência da metodologia ativa. (E9)

Questiona-se: Como o professor poderá desempenhar a função esperada pelo método da ABP, como ativador e mediador da aprendizagem (TSUJ; AGUILAR-DA-SILVA, 2010), se ele desconhece esse método de ensino, o PPC, e foi formado na metodologia tradicional?

Destaca-se a importância de o docente manter-se em permanente formação e acompanhando os movimentos, inovações e desenvolvimento do projeto pedagógico; no entanto o desconhecimento do professor acerca do PPC dificulta essa ação (TSUJI; AGUILAR-DA-SILVA, 2010).

A despreocupação e o desinteresse de o professor pelas questões pedagógicas têm origem em sua formação profissional baseada na transmissão de conhecimentos. A despreocupação caracteriza-se como fator dificultador para seu crescimento a respeito do conceito e vivência de metodologias de ensino e para a aplicação do ensino problematizador, que sustentam propostas curriculares flexíveis (MORAN; MASETTO; BEHRENS, 2000; CHIESA et al., 2007). O desinteresse pode estar relacionado ao fato de que geralmente espera-se do professor de Medicina um profundo conhecimento do assunto que deve ensinar, como se apenas esse aspecto assegurasse sua competência didática (COSTA, 2007).

Percebeu-se, a partir dos depoimentos dos entrevistados, o despreparo e a ausência de formação para o exercício da docência:

Eu nunca li nada de como se fazer habilidade, como planejar uma aula de habilidades. [...] isso surge da conversa entre professores, ou de como eu aprendi, 
enquanto estudante, como meus professores. (E8)

[...] eu estou repetindo alguma coisa do que eu aprendi. (E15)

Os docentes dos cursos médicos, na maioria das vezes, não têm como objeto de estudo questões referentes à profissão de professor que exercem, tornando-se limitada sua capacitação referente às atividades pedagógicas (MORAN; MASETTO; BEHRENS, 2000). Essa tem sido uma situação comum entre esses educadores, que em grande parte, aprenderam a ensinar observando seus professores ou refletindo sobre seu trabalho (WILKERSON; IRBY, 1998; HITCHCOCK; MYLONA, 2000), questão que se agrava com a inexistência, nas escolas médicas, de preparo específico no campo pedagógico (COSTA, 2007).

Esse despreparo faz com que o professor tente compensar essa situação ao exercer a docência relacionada às atividades de prática em sua área de atuação, de preferência dentro do serviço em que atua, conforme depoimento:

[...] tenho uma maior vivência da prática, e quero ficar na habilidade e atitude [...] assim como eu, muitos professores preferem o ambulatório. [...] é o que tenho mais competência, mais habilidade para fazer. (E1)

Percebe-se, aí, que, para o docente, a ABP limita-se às atividades de tutoria, o que demonstra ainda mais seu desconhecimento sobre a metodologia ativa de ensino-aprendizagem, que deve ser utilizada durante as diversas atividades desenvolvidas pelo professor, propostas no PPC, inclusive nos cenários reais de prática, que possibilitam a consolidação da construção do conhecimento pela participação ativa do estudante (TSUJI; AGUILAR-DA-SILVA, 2010). Evidencia-se a importância da formação profissional permanente dos docentes, sendo sua participação primordial em programas que adotam inovações pedagógicas como referência educacional (MACHADO; BATISTA, 2012; MACHADO et al., 2014).

Os professores discorrem sobre a organização das atividades docentes, baseadas em sua experiência da prática médica e espelhadas em outro colega, não contemplando orientação por parte da coordenação do curso:

[...] a gente se organizou por conta própria. (E9)

Os temas a gente que escolhe [...] qual conteúdo e a forma da aula, basicamente espelhamos nos colegas [...] em momento algum, fomos chamados pelo coordenador para falar: você precisa abordar estes temas, sugerimos ser desta forma, isso não tivemos em momento algum. (E3) 
Esse cenário condiz com uma prática na qual os professores ministram as aulas conforme suas conviç̧ões e repetem modelos vivenciados durante sua formação (TSUJI; AGUILAR-DA-SILVA, 2010). Compreende-se, portanto, que a trajetória docente tem sido influenciada pelo autodidatismo, com uma crença no esforço do próprio professor, na elaboração de saberes e na experiência como fundamentos que sustentam a docência em medicina (CANUTO; BATISTA, 2009).

Observou-se, neste estudo, que, diante da situação de falta de orientação, alguns professores procuram buscar no PPC do curso e na ementa de sua disciplina norteadores de suas atividades, como se pode perceber nos discursos:

[...] eu fui atrás do que estava no PPC, o que estava na ementa, o que teria que ser essa habilidade [...] busquei organizar a atividade para ele (o estudante) chegar a essa habilidade. (E10)

Para os entrevistados, o processo de ensino-aprendizagem encontra dificuldade pela desarticulação entre o ensino do conteúdo e a prática:

[...] porque a gente fica meio perdida. Será que ele já viu esse conteúdo na tutoria ou sou eu que devo passar para ele no ambulatório? [...] penso ser interessante o professor de habilidade saber realmente como é uma tutoria, principalmente realizar o entrelaçamento de conteúdos " [...] fica tudo solto, é uma quebra: o aluno com o preceptor na prática. (E15)

Essa conjuntura pode dificultar a superação da dicotomia entre teoria e prática, apontada como necessária pelas diretrizes curriculares nacionais, a fim de valorizar o trabalho articulado dos serviços de saúde com a população.

Numa dinâmica sobre a prática docente e seus fatores dificultadores, esses elementos têm interferido para que a ação do educador seja realizada com mais qualidade. Um dos fatores destacados pelos pesquisados diz respeito à falta de capacitação pedagógica, como percebido no relato abaixo:

[...] a forma de ensinar e avaliar o aluno, nisso o professor não é bem treinado

[...] falta o conhecimento sobre a abordagem pedagógica. (E1)

Tem-se percebido, na docência universitária geral, a deficiência no domínio da área educacional no desempenho docente (COSTA, 2007; MACHADO et al., 2014). O processo de reflexão sobre as práticas educativas utilizadas, muitas vezes, tem sido negligenciado; contudo, no presente estudo, percebeu-se que o professor tem feito essa reflexão, até mesmo identificando suas deficiências. 
No entanto, é importante ressaltar que esse movimento reflexivo deverá suscitar discussões, capacitações e consequentes mudanças de prática (COSTA, 2010). Os participantes também discorreram acerca da ausência de programas de capacitação dentro de sua realidade, reconhecendo sua importância para a prática docente, conforme percebido nos seguintes discursos:

Não temos programas de capacitação docente. O que solicitam é a capacidade como médico. [...] eu teria que ser capacitado para atender o aluno de forma pedagógica correta. (E14)

Torna-se necessária a capacitação docente para atuarmos como docentes: como perguntar, como comprovar e lidar com o estudante, a maneira como agir quando faltar um paciente. Vamos tendo ideias assim, na hora. (E18)

A pouca valorização dada à formação pedagógica do professor universitário tem sido relacionada à falta de investimento nas atividades de ensino nas universidades, nas quais os estímulos para atuação e os critérios de progressão na carreira têm-se fundamentado mais na produção científica que no exercício da docência (COSTA, 2010). Acrescenta-se a isso o menor investimento na remuneração do professor, que tem gerado a insatisfação docente diante do despendimento de tempo para essa prática e seu planejamento (COSTA, 2007).

Demonstra-se, aí a necessidade de programas de formação e desenvolvimento docente institucionalizados, entendendo a formação do professor como um processo permanente, em que seus saberes docentes se vão transformando à medida que empreendem seu trabalho pedagógico, problematizam e investigam sua própria prática (BATISTA; BATISTA, 1978; CAMPOS et al., 2007; MACHADO et al., 2014).

Essa circunstância pode estar relacionada às diversas atribuições profissionais que o professor de medicina apresenta, de forma que secundariza sua prática docente, o que pode caracterizar sua não profissionalização (CANUTO; BATISTA, 2009; COSTA, 2010). Além disso, a falta de integração e o individualismo em que se processa a docência configuram-se em um dos entraves ao desenvolvimento dos professores (COSTA, 2007).

Outro aspecto refere-se à heterogeneidade entre os docentes na mesma habilidade e a forma de conduzi-la, o que gera um descontentamento:

[...] em um mesmo periodo observo que cada professor toma uma direção diferente, por vezes divergente. A gente fica chateada. (E1) 
[...] há diferença no modo de conduzir a turma: um professor atende menos, outro discute mais a teoria. É preciso uma sintonia com a coordenação. (E13)

Relaciona-se a esse fato a ocorrência de que a prática docente se tem restringido à reprodução de modelos considerados válidos, apreendidos anteriormente, e à experiência prática cotidiana, o que tem refletido a formação não profissional dos docentes (MACHADO et al., 2014).

\section{Estratégias para o desenvolvimento docente}

Esta categoria revelou as estratégias que os professores entrevistados consideram úteis para melhorar a prática docente no módulo de Habilidades e Atitudes.

Os professores sugerem a importância da realização de cursos de capacitação para o aprendizado de técnicas mais adequadas, com o objetivo de instrumentar o docente para atividades coerentes com o PPC e o método ativo de aprendizagem. E ainda destacam a capacitação em pequenos grupos, coerente com a metodologia de ensino do curso.

\section{[...] eu teria que ser capacitado para trabalhar com o aluno [...]. (E11)}

[...] precisamos de grupos de discussão, principalmente com os professores que fazem as mesmas funções, que desenvolvem habilidades, e também com os que desenvolvem tutoria. (E15)

Uma das estratégias consiste no apoio dos professores mais experientes aos que iniciam as atividades em docência. Torna-se importante a orientação do coordenador de curso e apresentação do PPC norteador do curso e dos conteúdos a serem trabalhados.

[...] os temas a gente vai mudando de um professor para outro, mas a forma da aula, espelhamos nos colegas que trabalham na docência há mais tempo. (E9) [...] a outra professora... dividia comigo a habilidade. Ela me orientou sobre o que eu teria que fazer [...]. (E7)

Historicamente, o docente ligado ao curso de Medicina baseia sua prática educacional em modelos profissionais encontrados durante sua formação (GORDAN, 2004; TSUJI; AGUILAR-DA-SILVA, 2010), observando professores quando eram aprendizes, espelhando-se nos colegas, experimentando 
e refletindo sobre seu trabalho (WILKERSON; IRBY, 1998; HITCHCOCK; MYLONA, 2000), buscando adaptar-se à metodologia na qual estão inseridos:

[...] estou tentando adaptar; busco como meus professores me ensinaram; estou repetindo o modo como aprendi [...] tento aperfeiçoar [...]. (E9)

As mudanças impulsionadas por fatores intrínsecos e extrínsecos à educação exigem do professor universitário um novo perfil, que poderá ser construído via formação pedagógica de futuros docentes e por mudanças na cultura universitária, que, hoje, ainda valoriza tão diferentemente as atividades de docência e pesquisa (FERENC; MIZUKAMI, 2005).

Alguns estudos reconhecem a necessidade de formação educacional permanente dos docentes (HITCHCOCK; MYLONA, 2000; VENTURELLI; FIORINI, 2001; TSUJI; AGUILAR-DA-SILVA, 2010) e enfatizam a importância da formação de todos os educadores da instituição. Assim, justifica-se a necessidade de implantar, nas instituições acadêmicas, programas de desenvolvimento docente que ajudem a aprimorar habilidades para planejamento curricular, melhorar o ensino e promover a excelência acadêmica (WILKERSON; IRBY, 1998; VENTURELLI; FIORINI, 2001). Além disso, para se atingir o aperfeiçoamento na docência é necessário um programa sistemático objetivando desenvolver competências para progredir na carreira (GORDAN, 2004).

Por se tratar da utilização de estratégias, cujos atores envolvidos são ativos, os docentes ressaltam a importância da construção coletiva como uma forma de amenizar a heterogeneidade de condutas e as possíveis divergências que possam surgir, realizando reuniões com os docentes que ministram a mesma habilidade.

[...] temos que reunir, com um objetivo norteador: como fazer, para que todos façam de forma semelhante [...]. (E3)

O ensino é dependente da qualidade coletiva das equipes que efetivam o trabalho de forma solidária (RAMOS, 1994), e é fundamental o exercício da cooperação e integração docente, fortalecendo os grupos de trabalho no sentido de estimular a qualificação dos professores.

A troca de experiências e a partilha de saberes concretizam espaços de formação mútua, nos quais cada docente é chamado a desempenhar, simultaneamente, o papel de educador e educando. Assim, as práticas de formação contínua, considerando a coletividade, contribuem para a emancipação profissional e para a consolidação de uma profissão que é autônoma na produção de seus saberes e de seus valores (NÓVOA, 2002). 
A comunicação interativa entre os campos do conhecimento é requisito básico para ações interdisciplinares e superação do modelo da educação tradicional. A ação coletiva das pessoas e/ou do grupo, promovendo a interação docente, busca resgatar o pensamento da dimensão fragmentada e da visão disciplinar das especialidades (MACHADO, 2009). A importância de estabelecer relações entre os módulos de conteúdo específico e módulo de habilidade no curso médico é também bastante enfatizada:

[...] o módulo (de habilidades e atitudes) que eu estou, está bem articulado com o módulo de conteúdo especifico [...]. (E13)

[...] e observo um melhor aproveitamento pelo estudante, ao perceberem que os professores tem uma interação com o módulo que estão estudando. Conseguem relacionar a prática e o conteúdo específico. (E6)

Quanto ao processo de ensino-aprendizagem, para o professor torna-se indispensável a clareza dos conteúdos e das relações entre as disciplinas (MASETTO, 2002). Soma-se a isso a necessidade de capacitação, interação, respeito à singularidade, ética e habilidade, para lidar com as emoções e flexibilidade, mantendo uma postura de participação cooperativa, coletiva e integradora (FARIA et al., 2008).

Dentre os interesses demonstrados pelos docentes, está a revisão constante e a compreensão da proposta do PPC como ponto fundamental para a utilização dos métodos ativos. Demonstram interesse na capacitação e desenvolvimento docente, com a finalidade de conhecer, desenvolver a habilidade e seu conteúdo. Priorizam trabalho em parceria, corresponsabilidade, integração das competências pedagógicas e científicas dos envolvidos.

[...] muitos professores organizam-se por conta própria, no conteúdo, e na forma de trabalhar com os estudantes.... (E2)

[...] ao iniciar na docência, seria importante a orientação pela Coordenação do curso, além do conhecimento do PPC, e da ementa da disciplina [...]. (E18)

A compreensão plena do modelo pedagógico pode colaborar para diminuir a sensação de ambiguidade dos integrantes do processo tutorial e, por conseguinte, melhorar qualitativamente as tutorias. Essa compreensão pode contribuir da mesma forma no resultado e qualidade dos módulos de Habilidades e Atitudes (TSUJI; AGUILAR-DA-SILVA, 2010). 
Os professores reconhecem a necessidade de mudanças na prática docente em saúde e discutem a necessidade da formação do educador reflexivo.

[...] precisamos discutir qual habilidade e atitudes o docente deve trabalhar. [...] e cada um deve fazer a sua reflexão e crítica [...]. (E11)

O poder e a importância do diálogo, na busca da interação dos saberes entre os docentes, destacam-se como elemento imprescindível na construção da prática dialógica, comunicativa, em um cenário interdisciplinar (MACHADO; BATISTA, 2012). Autores concordam que o corpo docente é o alicerce sobre o qual devem ser instituídas, sustentadas e consolidadas as mudanças necessárias à formação de profissionais da área da saúde (FARIA et al., 2008; LAMPERT et al., 2009; PERIM et al., 2009; COSTA, 2010).

\section{Considerações Finais}

Os docentes de medicina dos módulos de Habilidades e Atitudes têm compreendido a competência como conhecimento adquirido na experiência profissional e na prática. Esses profissionais têm ingressado na carreira de educadores, geralmente, sem possuir capacitação pedagógica para a atuação docente, apesar da habilidade médica, em sua especialidade. Diante disso, a ação docente tem sido fundamentada na experiência vivenciada em seu processo de formação, espelhando-se em seus mestres.

Para alguns, há um desconhecimento sobre as competências docentes descritas no PPC. É notória a necessidade de promover o desenvolvimento pedagógico desses docentes, além da compreensão acerca da importância na formação do futuro médico.

Para tanto, recomenda-se a implementação de um programa de desenvolvimento do corpo docente, que se tornará um valioso instrumento de reflexão no que diz respeito aos educadores e seu envolvimento na percepção da competência.

Atuar como professor no curso médico exige técnicas e conhecimento, além da compreensão do conceito de competências, habilidades e atitudes de tal forma que envolva a ciência teórica, a experiência prática e o conhecimento pedagógico. 


\section{Referências}

AZEVEDO, Bruno Mariani de Souza et al. A formação médica em debate: perspectivas a partir do encontro entre instituição de ensino e rede pública de saúde. Interface (Botucatu), Botucatu, v. 17, n. 44, p. 187200, mar. 2013. Disponível em: $<$ http://www.scielo.br/scielo.php?script=sci arttext\&pid=S1414-32832013000100015\&lng=en\&nrm=iso\&tlng $=\mathrm{pt}>$. Acesso em: 10 fev. 2015.

BATISTA, Nildo Alves; BATISTA, Sylvia Helena Souza da Silva. Docência em Saúde: temas e experiências. São Paulo: Imago, 1978.

BRASIL. Ministério da Educação. Conselho Nacional de Educação. Câmara de Educação Superior. Resolução CNE/CES No 3 de 20/06/2014. Diretrizes Curriculares Nacionais do Curso de Graduação em Medicina. Diário Oficial da União, Brasília, DF, seção 1, p. 8-11, jun. 2014. Disponível em: <http:// www.fmb.unesp.br/Home/Graduacao/resolucao-den-2014.pdf >. Acesso em: 25 jan. 2015.

CAMPOS, Henry de Holanda et al. Programas de Desenvolvimento Docente em Escolas Médicas: Oportunidades e Perspectivas - mais do que uma necessidade. Cadernos ABEM, Rio de Janeiro, v. 3, p. 34-38, out. 2007. Disponível em: $<$ https://www.ufpe.br/medicina/images/Textos recomendados/programas_de_desenvolvimento_docente.pdf $>$. Acesso em: 25 jan. 2015.

CANUTO, Ângela Maria Moreira; BATISTA, Sylvia Helena Souza da Silva. Concepções do processo ensino aprendizagem: um estudo com professores de medicina. Revista Brasileira de Educação Médica, Rio de Janeiro, v. 33, n. 4, p. 624-632, out/dez. 2009. Disponível em: <http://www.scielo.br/ scielo.php?script $=$ sci_arttext\&pid $=$ S0100-55022009000400013\&lng=en\&nr $\mathrm{m}=\mathrm{iso} \& \mathrm{t} \operatorname{lng}=\mathrm{pt}>$. Acesso em: 22 out. 2014.

CHIESA, Anna Maria et al. A formação de profissionais da saúde: aprendizagem significativa à luz da promoção da saúde. Cogitare Enfermagem, Curitiba, v. 12, n. 2, p. 236-40, abr/jun. 2007. Disponível em: $<$ http://revistas.ufpr.br/cogitare/article/view/9829/6740. $>$. Acesso em: 22 out. 2014. 
COSTA, Nilce Maria da Silva Campos. Docência no ensino médico: por que é tão difícil mudar? Revista Brasileira de Educação Médica, Rio de Janeiro, v. 31, n.1, p. 21-30, abr. 2007. Disponível em: < http://www.scielo. br/scielo.php?script=sci_arttext\&pid=S0100-55022007000100004\&lng=en $\& n r m=i s o \& t l n g=p t>$. Acesso em: 26 jun. 2014.

COSTA, Nilce Maria da Silva Campos. Pedagogical training of medicine professors. Revista Latino-Americana de Enfermagem, Ribeirão Preto, v. 18, n.1, p. 102-108, jan./fev. 2010. Disponível em: < http://www.scielo. br/scielo.php?script=sci_arttext\&pid=S0104-11692010000100016 $>$. Acesso em: 26 jun. 2014.

FARIA, Maria José Sparça Salles de et al. Os desafios da educação permanente: a experiência do curso de Medicina da Universidade Estadual de Londrina. Revista Brasileira de Educação Médica, Rio de Janeiro, v. 32, n. 2, p. 248-253, abr/jun. 2008. Disponível em: <http://www.scielo.br/ scielo.php?script $=$ sci_arttext\&pid $=$ S0100-55022008000200013>. Acesso em: 26 jun. 2014.

FERENC, Alvanize Valente Fernandes; MIZUKAMI, Maria da Graça Nicoletti. Formação de professores, docência universitária e o aprender a ensinar. In: CONGRESSO ESTADUAL PAULISTA SOBRE FORMAÇÃO DE EDUCADORES, 8., 2005, São Paulo, SP. Anais... São Paulo, 2005.

FRANCO, Renato Soleiman et al. O conceito de competência: uma análise do discurso docente. Revista Brasileira de Educação Médica, Rio de Janeiro, v. 38, n. 2, p. 173-181, abr/jun. 2014. ISSN 0100-5502. Disponível em: $<$ http://www.scielo.br/scielo.php?script=sci_arttext\&pid $=$ S0100-55022014000200003 >. Acesso em: 20 fev. 2015 .

FREIRE, Paulo. Pedagogia da autonomia: saberes necessários à prática educativa. 2. ed. São Paulo: Paz e Terra, 1997.

GADAMER, Hans-Georg. Verdade e método. 3. ed. Petrópolis: Vozes, 1999.

GORDAN, Pedro Alejandro. Currículos inovadores: o desafio da inserção docente. In: BATISTA, Nildo Alves; BATISTA, Sylvia Helena (Org.).

Docência em saúde: temas experiências. São Paulo: Senac, 2004. v. 1, p. 187-200. 
HITCHCOCK, Maurice A.; MYLONA, Zoi-Helen Elza. Teaching faculty to conduct problem-based learning. Teaching and Learning Medicine, Philadelphia, v. 12, n. 1, p. 52-57, 2000.

LAMPERT, Jadete Barbosa et al. Tendências de mudanças em um grupo de escolas médicas brasileiras. Revista Brasileira de Educação Médica, Rio de Janeiro, v. 33, supl.1, p. 19-34, 2009. Disponível em: < http://www.scielo. br/scielo.php?script=sci_arttext\&pid=S0100-55022009000500003 $>$. Acesso em: 26 jun. 2014.

MACHADO, Maria das Mercês Borém Corrêa. A interdisciplinaridade na construção dos conteúdos curriculares do Curso Médico da Unimontes. Dissertação (Mestrado) -Universidade Federal de São Paulo, São Paulo, 2009.

MACHADO, Maria das Mercês Borém Corrêa; BATISTA, Sylvia Helena Souza da Silva. Interdisciplinaridade na construção dos conteúdos curriculares do curso médico. Revista Brasileira de Educação Médica, Rio de Janeiro, v. 36, n. 4, p. 456-462, out/dez. 2012. Disponível em: $<$ http://www.scielo.br/scielo.php?script=sci_arttext\&pid $=$ S0100-55022012000600003>. Acesso em: 26 jun. 2014.

MACHADO, Maria das Mercês Borém Corrêa et al. Programa de desenvolvimento docente: fator estratégico para o processo de mudança curricular no curso médico. Revista Intercâmbio, Montes Claros, v. 5, p. 111-124, 2014. Disponível em: <http://www.intercambio.unimontes.br/ index.php/intercambio/article/view/44/44>. Acesso em: 20 jun. 2015.

MASETTO, Marcos Tarciso. Docência na universidade. 4. ed. Campinas: São Paulo: Papirus, 2002.

MINAYO, Maria Cecília de Souza. O desafio do conhecimento: pesquisa qualitativa em saúde. 12. ed. São Paulo: Hucitec, 2010.

MORAN, José Manuel; MASETTO, Marcos Tarciso; BEHRENS, Marilda Aparecida. Novas tecnologias e mediação pedagógica. Campinas: Papirus, 2000.

NÓVOA, António. Formação de professores e trabalho pedagógico. Lisboa: Educa, 2002. 
PÊCHEUX, Michel. Estrutura ou acontecimento. 3. ed. Campinas: Pontes, 2002.

PERIM, Gianna Lepre et al. Desenvolvimento docente e a formação de médicos. Revista Brasileira de Educação Médica, Rio de Janeiro, v. 33, supl.1, p. 70-82, 2009. Disponível em: $<$ http://www.scielo.br/scielo. php?script $=$ sci_arttext\&pid=S0100-55022009000500008 $>$. Acesso em: 26 jun. 2014.

PIMENTA, Selma Garrido; ANASTASIOU, Lea das Graças Camargo. Docência no ensino superior. São Paulo: Cortez, 2002.

PINHEL, Inahiá; KURCGANT Paulina. Reflexões sobre competência docente no ensino de enfermagem. Revista da Escola de Enfermagem da USP, São Paulo, v. 41, n. 4, p. 711-716, dez. 2007. Disponível em: $<$ http://www.scielo.br/scielo.php?script=sci_arttext\&pid $=$ S0080-62342007000400024 $>$. Acesso em: 26 jun. 2014 .

RAMOS, Cosete. Pedagogia da qualidade total. Rio de Janeiro: Qualitymark, 1994.

RICOEUR, Paul. O conflito das interpretações: ensaios de hermenêutica. Rio de Janeiro: Imago, 1978.

TSUJI, Hissachi; AGUILAR-DA-SILVA, Rinaldo Henrique. Aprender e ensinar na escola vestida de branco: Do modelo biomédico ao humanístico. São Paulo: Forte, 2010.

UNIVERSIDADE ESTADUAL DE MONTES CLAROS - UNIMONTES. Projeto Pedagógico do Curso de Medicina. Montes Claros, 2014.

VENTURELLI, José; FIORINI, Vânia Maria. Programas Educacionais Inovadores em Escolas Médicas: Capacitação Docente. Revista Brasileira de Educação Médica, Rio de Janeiro, v. 25, p. 7-21, 2001.

WILKERSON, Luann; IRBY, David M. Strategies for improving teaching practices: acomprehensive approach to faculty development. Academic medicine: journal of the Association of American Medical Colleges, Washington, DC, v. 73, n. 4, p. 387-396, abr. 1998. 
Maria das Mercês Borém Correa Machado - Universidade Estadual de Montes Claros | Montes Claros | MG | Brasil. Contato: mercesborem@gmail.com

Cristina Andrade Sampaio - Universidade Estadual de Montes Claros Montes Claros | MG | Brasil. Contato: cristina.sampaio@unimontes.br

Simone Moreira de Macedo - Universidade Federal do Espírito Santo

Vitória | ES | Brasil. Contato: simonemoreira.macedo@gmail.com

Maria Fernanda Santos Figueiredo - Universidade Estadual de Montes Claros Montes Claros | MG | Brasil. Contato: nanda_sanfig@yahoo.com.br João Felício Rodrigues Neto - Universidade Estadual de Montes Claros Montes Claros | MG | Brasil. Contato: joaofelicio@yahoo.com Isabella Gomes Lopes - Universidade Estadual de Montes Claros Montes Claros | MG | Brasil. Contato: isabellal3@hotmail.com

Maísa Tavares de Souza Leite - Universidade Estadual de Montes Claros Montes Claros | MG | Brasil. Contato: mtsiv@terra.com.br

Artigo recebido em 20 de junho de 2015 e aprovado em 7 de dezembro de 2015 . 